\title{
Influence of Life Satisfaction on Self-Esteem Among Young Adults: The Mediating Role of Self-Presentation
}

\section{Małgorzata Szcześniak (1) \\ Paulina Mazur \\ Wojciech Rodzeń (DD \\ Kamila Szpunar}

Institute of Psychology, University of Szczecin, Szczecin, 7I-0I7, Poland
Correspondence: Małgorzata Szcześniak Email malgorzata.szczesniak@usz.edu.pl
Background: A comprehensive literature review suggests that self-esteem seems to be contingent on being satisfied in various domains of life. Although there are multiple studies that have addressed the direct relationship between both variables, there is still little known about the psychological mechanisms that underlie this association. Since self-presentation is an important process in young adulthood, the main goal of the present study was to consider self-promotion and self-deprecation as potential mediators between life satisfaction and self-esteem.

Participants, Methods and Data Collection: The study included 328 young adults aged between 18 and 35. Most of them were women (74.1\%). The data were collected in Poland through an anonymous self-administered battery of questionnaires on the Internet platform. The participants completed the Satisfaction with Life Scale, the Rosenberg Self-Esteem Scale, and the Self-Presentation Style Questionnaire.

Results: A high and positive correlation coefficient was obtained between self-esteem and life satisfaction $(r=0.73 ; p<0.001)$. The level of self-esteem correlated positively with the style of self-promotion $(r=0.46 ; p<0.001)$ and negatively with the style of self-deprecation $(r=-0.63$; $p<0.001)$. Similarly, life satisfaction was positively associated with self-promotion $(r=0.37 ; p<$ $0.001)$ and negatively with self-depreciation $(r=-0.42 ; p<0.001)$. Moreover, both selfpromotion $(\beta=0.67 ; p<0.001)$ and self-deprecation $(\beta=0.58 ; p<0.001)$ acted as mediators between life satisfaction and self-esteem.

Conclusion: The present study increases our knowledge about the mediatory role of selfpromotion and self-deprecation. An overall sense of satisfaction with one's own life can lead to higher self-esteem when young people are aware of their strengths and talents. Likewise, lower life satisfaction can elicit less positive self-esteem when people tend to undervalue their capabilities.

Keywords: life satisfaction, self-esteem, self-presentation, self-promotion, self-deprecation, young adults, mediation

\section{Introduction}

Self-esteem is a complex, subjective construct which reflects an individual's perception, emotional evaluation, and acceptance of the self. ${ }^{1-6}$ Researchers advocate that self-esteem is relatively stable throughout life, ${ }^{7-9}$ increases in young adulthood, ${ }^{10}$ and varies across cultures. ${ }^{11}$ In some social contexts and religions, self-esteem and self-worth come from the very fact of being a human being, and in others, self-esteem depends on what people are or do. ${ }^{7,12}$

Considering the second perspective, some theorists emphasize that an individual's self-esteem may be an outcome variable ${ }^{13}$ and depends on several factors 
such as: socialization processes ${ }^{14,15}$ social, cognitive, and biological changes, ${ }^{7}$ quality of one's interpersonal relationships, ${ }^{16-18}$ others' approval/inclusion or rejection/ exclusion, ${ }^{19-21}$ personal beliefs, ${ }^{22}$ values, ${ }^{11,23,24}$ and success or failures in pursuing one's goals. ${ }^{12,25}$ In other words, people's self-esteem seems to be contingent on being satisfied in various domains of life. ${ }^{26}$

Researchers define subjective well-being (SWB) in different ways, referring to the two main historical views of hedonism and eudaimonia. ${ }^{27,28}$ The hedonic dimension of SWB alludes to pleasant or unpleasant affective aspects of people's judgment about their lives. $^{29-31}$ The eudaimonic component of well-being implies a valuable life, ${ }^{30}$ accentuates personal meaning and growth, ${ }^{32}$ deals with purpose in life, ${ }^{33}$ and indicates virtuous excellence. ${ }^{34}$ Another model of well-being refers to the tripartite structure of SWB by Diner et $\mathrm{al}^{35}$ that contains three primary components: positive affect, negative affect, and life satisfaction. The two former elements have an emotional character and the latter has a cognitive one. In our study, we refer to the conceptualisation which identifies life satisfaction as "a distinct construct representing a cognitive and global evaluation of the quality of one's life as a whole" (p. 137). ${ }^{36}$

A comprehensive literature review suggests that the directionality of the relations between self-esteem and general satisfaction or its different types is unclear. ${ }^{37}$ Past research has mainly shown that self-esteem acts as a strong predictor of life satisfaction. ${ }^{13,14}$ Such an approach reflects bottom-up theories of SWB which consider particular variables as determinants of life satisfaction. $^{38,39}$ Less attention, however, has been given to whether overall satisfaction or its various dimensions may be predictors of self-esteem. ${ }^{13,37}$ This approach represents top-down theories which consider life satisfaction as a factor that produces certain outcomes. ${ }^{38,39}$ According to this perspective, people first evaluate their general life satisfaction and then depend on this assessment when considering more specific domains. ${ }^{40}$ In other words, a comprehensive disposition to experience things in a positive way has its effect on people's interactions with the world and the self. ${ }^{41}$

Given that life satisfaction, understood as a cognitive judgmental process based on individual evaluation of one's life in general $^{36}$ or specific domains, ${ }^{42}$ can be an antecedent to self-esteem, we took this line of analysis in the present research. In this respect, Baumeister et $\mathrm{al}^{43}$ have assumed that self-esteem can not only cause a variety of positive outcomes, but can itself be an outcome of success as well. Similarly, Brown et $\mathrm{al}^{13}$ have noticed that a broad range of experiences influence the way people perceive, think, and feel about themselves. Moreover, Diener and Diener ${ }^{14}$ have found that friend, family, and financial satisfaction are predictors of selfesteem. In fact, Goldsmith et al ${ }^{44}$ have observed that selfesteem may be modified by important life alterations or distressing circumstances. In turn, Barker and Bornstein ${ }^{37}$ have suggested that satisfaction with one's appearance might help in raising people's global self-esteem. A recent longitudinal study ${ }^{45}$ has shown that satisfaction with one's relationship affects self-esteem. People who consider their lives as satisfied have increased selfconfidence and self-efficacy. ${ }^{46} \mathrm{Neff}^{47}$ has observed that self-esteem is predominantly the outcome of doing well. On the basis of the abovementioned studies, we hypothesized that:

H1: Life satisfaction is positively related to self-esteem.

Multiple studies have addressed the direct relationship between life satisfaction and self-esteem ${ }^{3,36,48-54}$ but the psychological mechanisms that underlie this association are still unknown. Therefore, the present research has attempted to go beyond the direct link between both constructs by examining the potential mediator of self-presentation. In fact, young people tend to engage in self-presentation to explore their identity ${ }^{55}$ and strengthen their self images. ${ }^{56}$ The choice of self-presentation was dictated by the fact that young adults are particularly sensitive to this aspect of their functioning. Therefore, both self-promotion and selfdeprecation seem not indifferent to experiencing selfesteem in the context of life satisfaction.

The term "self-presentation" usually refers to people's endeavors to convey an image of the self to others ${ }^{57}$ and to control impressions of themselves. ${ }^{58,59}$ In this sense, selfpresentation can also be defined as a skill consisting of the selective presentation of one's self to others. ${ }^{60}$ Selfpresentation can be manifested through different forms of self-promotion or its opposite, self-deprecation. ${ }^{61}$ People who self-promote enhance aspects of the self, ${ }^{62}$ tend to emphasize their competence, strengths, talents, ${ }^{63-65}$ point with pride to their own accomplishments and make internal attributions for success. ${ }^{66}$ On the contrary, individuals who assume self-depreciative behavior create their own image as being incompetent, insecure, and helpless. ${ }^{67}$ Selfdeprecation refers to negative self-evaluation, ${ }^{68}$ the 
tendency to denigrate or disparage one's own capabilities, ${ }^{69}$ feeling unworthy or inferior.

The literature on self-presentation has verified that selfpromotion contributes to favorable outcomes, ${ }^{63}$ subjective vitality, ${ }^{70}$ and well-being. ${ }^{71}$ Although there is little empirical evidence on the relationship between life satisfaction and self-promotion, a number of studies have shed light on this association. For instance, Wojciszke ${ }^{57}$ has found that successful, well-educated women working in managerial positions in various types of companies are more prone to self-promotion and less to self-deprecation than welleducated nurses employed as secondary medical personnel in the health service. Given that education matters to subjective quality of life $^{72}$ and relates to self-promotion ${ }^{57}$ it is reasonable to infer that satisfaction with the quality of one's own life is related to engagement in self-promotion. With respect to self-deprecation, it has been confirmed that people who feel more lonely, ${ }^{73}$ have more negative emotions, ${ }^{69}$ declare lower levels of life satisfaction, ${ }^{74}$ fear being laughed at, ${ }^{67}$ and have difficulty coping with stressors in their daily life ${ }^{75}$ deprecate their value. In fact, life satisfaction, considered as the evaluation of people's overall quality of life, expresses “one's liking or disliking of one's life" (p. 574). ${ }^{76}$ It can be assumed that satisfaction might be positively tied to self-promotion, and negatively to self-deprecation. Moreover, drawing on the top-down theories mentioned earlier, it can be presumed that life satisfaction may influence both dimensions of selfpresentation. The more satisfied someone is with their life, the more likely they are to enhance aspects of the self. Conversely, lower satisfaction may be manifested by a lower level of competence or security. Consistent with this line of research, we hypothesized that:

H2: Life satisfaction is positively related to selfpromotion, and negatively associated with selfdeprecation.

Finally, consideration of self-promotion and selfdeprecation as potential mediators between life satisfaction and self-esteem also requires both styles of self-presentation to be related to self-esteem. According to some researchers, ${ }^{57,77,78}$ individuals with genuinely high selfesteem adopt self-promotion as one of the self-presentation styles. Likewise, McGregor et $\mathrm{al}^{79}$ have shown that selfpromoting behaviors have been found among people with high self-esteem. In other words, emphasizing one's own abilities characterizes high ${ }^{80}$ and secure $^{81}$ self-esteem subjects. Instead, self-deprecation tends to correlate negatively with self-esteem. According to Neenan and Dryden, ${ }^{82}$ self-deprecation manifests itself when self-esteem falls. Peteet et $\mathrm{al}^{83}$ have found that impostorism, conceptually closed to self-deprecation, is associated with deficient psychological functioning and low self-esteem. Although there is a lack of studies regarding the mediatory effect of selfpromotion or self-deprecation on the relationship between life satisfaction and self-esteem, on the basis of the presented empirical evidence, we hypothesized that:

H3: Self-promotion and self-deprecation act as mediators between life satisfaction and self-esteem.

In brief, our main goal was to verify whether or not a subjective evaluation of people's life can have a greater/ lower impact on their overall sense of worth when they improve/impair their strengths and talents.

\section{Methods}

\section{Participants and Data Collection}

The study included 328 young adults -243 women $(74.1 \%)$ and 85 men $(25.9 \%)$ aged 18 to $35(M=23.02 ; S D=3.80)$. The data were collected in Poland through an anonymous self-administered battery of questionnaires on the Internet platform. University students of psychology were invited to participate in the study and to reach other young adults, both friends and family members. The present research relied on a convenience sample as such a methodology is costeffective, efficient, and simple to implement. ${ }^{84}$ The inclusion criteria were related to the age of young adulthood since self-promotion is a commonly used strategy in this developmental period. ${ }^{85}$ All of the respondents were given insight into the purpose of the study, including the confidentiality of the data. They were also prompted with a web-based informed consent. After confirming their agreement, the participants were solicited to complete the questionnaires. The study was approved by the Bioethics Committee of the Institute of Psychology at the University of Szczecin (KB 12/2021) and conducted in compliance with ethical guidelines provided by the Declaration of Helsinki.

\section{Measurement}

Satisfaction with Life Scale (SWLS). A self-report tool used to measure the overall level of satisfaction ${ }^{35}$ in the Polish adaptation of Juczyński. ${ }^{86}$ The one-factor scale consists of five items (eg: So far I have got the important things I want in life). The examined person assesses the extent to which 
each of the statements applies to his or her life. The answers are given using a seven-point Likert scale (from 1 "strongly disagree" to 7 - "strongly agree"). The higher the score obtained, the higher the level of overall satisfaction with life. The scale is characterized by a high value of the reliability index. In fact, in the present study, $\alpha$ was 0.89 .

Rosenberg Self-Esteem Scale (SES). A self-report research tool created by Rosenberg ${ }^{87}$ in the Polish version by Łaguna et al $^{88}$ used to measure the general level of self-esteem - the global attitude toward the self, as a conscious and relatively constant self-assessment. The one-dimensional scale consists of 10 items (eg: I am able to do things as well as most other people). The respondent's task is to indicate on a four-point scale (from 1 "strongly agree" to 4 - "strongly disagree") to what extent he or she agrees with each of the statements. The higher the overall score obtained, the higher the self-assessment level. High self-esteem means the belief that you are a valuable person (not necessarily in comparison with others), and low self-esteem means dissatisfaction with yourself, rejection of your own self. The responses to five statements are scored inversely. The present study obtained a high value of Cronbach's alpha reliability coefficient ( $\alpha=0.92$ ).

Self-Presentation Style Questionnaire (SSQ). A two-factor tool, developed by Wojciszke, ${ }^{57}$ used to measure styles of self-presentation, understood as intentional behavior aimed at modifying the way other people perceive oneself and making the desired impression on others. The questionnaire consists of 30 items forming two factors that make up the distinguished styles of self-presentation: self-promotion - presenting oneself as a competent person (eg: I emphasize my own merits), and self-deprecation - creating oneself as a modest and not very competent person (eg: I belittle the importance of my achievements). The participant responds to all statements using a 5-point scale (from 1 - "never" to 5 - "very often"). The current study obtained high $\alpha$ values of Cronbach's alpha reliability coefficients for both styles of self-presentation: selfpromotion $(\alpha=0.87)$ and self-deprecation $(\alpha=0.83)$. Both values were very similar to the original results: self-promotion $(\alpha=0.87)$ and self-deprecation $(\alpha=0.82) .^{57}$

\section{Statistical Analysis}

All calculations were performed using IBM SPSS Statistics 25.0 with a $95 \%$ confidence level. Due to the electronic method, no missing data were identified among the analyzed observations. Prior to the major statistical analyses, the data were validated for outliers using the
Mahalanobis, Cook's distance indicators and impact values. Failure to meet two of the three assumptions of the distance indicators used was adopted as the criterion for rejecting observations. In order to estimate the degree of correlation between all of the variables, calculations were performed using the Pearson correlation coefficient.

The main statistical calculations concerned the analysis of the two simple mediation models using the bootstrapping method with a random selection of 5000 samples using the PROCESS macro 3.4. ${ }^{89}$ The rationale to consider only one mediator model and not two parallel mediation models including both types of self-presentation was that while we expected self-promotion and selfdepreciation to correlate, their association was suspected to be negative. Therefore, we treated both dimensions as separate ones. In both analyzed models, the independent variable $(\mathrm{X})$ was life satisfaction, the dependent variable (Y) was the level of self-esteem, and the mediator (M) was the selected style of self-presentation - self-promotion in model 1 and self-deprecation in model 2.

\section{Results \\ Descriptive Statistics}

The values of the mean, standard deviation, skewness, and kurtosis tests are presented in Table 1. Despite the statistically significant $(p<0.001)$ values of the normality test, the skewness and kurtosis values were in a relatively low range of \pm 1 .

Life satisfaction, self-esteem, self-promotion, and selfdeprecation were screened for skewness and kurtosis to evaluate the normality of the scales' distributions. We adopted indices less than the \pm 2 which are considered the acceptable limits of a normal distribution. No variables exceeded the cutoffs of \pm 2 (Table 1 ).

\section{Correlations}

The conducted analysis with the use of Pearson's $r$ correlation coefficient (Table 2 ) showed statistically significant $(p<0.01)$ correlations between all measured variables.

A high and positive correlation coefficient was obtained between the variables self-esteem and life satisfaction $(r=0.73)$. The level of self-esteem correlated positively with the style of self-promotion $(r=0.46)$ and negatively with the style of self-deprecation $(\mathrm{r}=-0.63)$. A similar relationship was observed between life satisfaction and both styles of self-presentation - self-promotion $(r=0.37)$ and self-deprecation $(r=-0.42)$. 
Table I Descriptive Statistics for Life Satisfaction, Self-Esteem, Self-Promotion, and Self-Deprecation ( $N=328)$

\begin{tabular}{|l|c|l|l|l|l|l|}
\hline Variable & M & SD & Min & Max & Skewness & Kurtosis \\
\hline Life satisfaction & 41.27 & 9.35 & 5 & 35 & -0.370 & -0.369 \\
Self-esteem & 29.44 & 7.89 & 10 & 40 & 0.157 & -0.323 \\
Self-promotion & 18.93 & 7.71 & 15 & 75 & 0.029 & -0.851 \\
Self-deprecation & 15.13 & 7.50 & 15 & 75 & 0.487 & -0.497 \\
\hline
\end{tabular}

\section{Mediation Analyses}

The conducted two simple mediation analyses showed statistically significant values of standardized regression coefficients for both models (Table 3). The regression coefficient between the independent variable and the dependent variable had a high and positive initial value $(\beta=0.75 ; p<0.001)$. The strength of the total indirect effect was higher for the model with the self-deprecation style as a mediator (total indirect effect $=0.18$ ) than for the self-presentation tactics based on self-promotion (total indirect effect $=0.07$ ). For both analyzed models, the confidence interval did not contain the value "0", which proves their statistical significance.

For the first model (LS-SP-SE), positive and statistically significant $(p<0.001)$ values of the regression coefficients were observed between life satisfaction $(\mathrm{X})$ and selfpromotion $(\mathrm{M})$ - path a $(\beta=0.47)$, and between the style of self-promotion $(\mathrm{M})$ and self-esteem $(\mathrm{Y})$ - path $\mathrm{b}(\beta=0.17)$. After adding the mediator in the form of self-promotion tactics to the analyzed dependencies, the initial value of the regression coefficient decreased from $\beta=0.75$ (c) to $\beta=0.67$ (c') without changing the significance level.
Correspondingly, in the second analyzed model, statistically significant $(p<0.001)$ and negative standardized values of regression coefficients were identified between the variable life satisfaction $(\mathrm{X})$ and self-deprecation $(\mathrm{M})$ path a $(\beta=-0.56)$ and self-deprecation $(\mathrm{M})$ and selfesteem $(\mathrm{Y})$ - path $\mathrm{b}(\beta=-0.32)$. Moreover, according to the obtained higher value of the total indirect effect for the second model, the initial value of the regression between the independent and the dependent variable $(\beta=$ $0.76)$ decreased to a greater extent than in the case of the first analyzed model $(\beta=0.58)$.

\section{Discussion}

The present research confirmed that: life satisfaction positively relates to self-esteem (H1) and self-promotion (H2), life satisfaction is negatively associated with selfdeprecation (H2), and both self-promotion and selfdeprecation act as mediators between life satisfaction and self-esteem (H3).

Firstly, it is comprehensible that considering one's own life satisfactory and successful might reinforce the belief of young adults as good and worthy. In fact, different studies have shown that self-esteem increases when people achieve their desired aims, ${ }^{90,91}$ gain job promotions, ${ }^{92}$ feel they are doing well in life, ${ }^{93}$ effectively cope with psychological threats, ${ }^{94}$ have selfperceived competence, ${ }^{95}$ maintain good interpersonal relationships, ${ }^{58}$ and receive appreciative ${ }^{90}$ and meaningful messages from significant others. ${ }^{96}$ All of these

Table 2 Obtained Values of the Pearson Correlation Coefficient Between the Analyzed Variables

\begin{tabular}{|l|c|c|c|c|}
\hline & Life Satisfaction & Self-Esteem & Self-Promotion & Self-Deprecation \\
\hline Life satisfaction & $\mathrm{I}$ & - & - & - \\
Self-esteem & $0.73^{* * *}$ & $\mathrm{I}$ & - & - \\
Self-promotion & $0.37^{* * *}$ & $0.46^{* * *}$ & $\mathrm{I}$ & - \\
Self-deprecation & $-0.42^{* * *}$ & $-0.63^{* * *}$ & $-0.44^{* * *}$ & $\mathrm{I}$ \\
\hline
\end{tabular}

Note: $* * * p<0.001$.

Table 3 Results of Mediation Analyses for Both Models (Standardized Values)

\begin{tabular}{|l|c|c|c|c|c|c|c|}
\hline Mediation Model & a & b & c & \multirow{2}{*}{ c' } & Total Indirect Effect & \multicolumn{2}{|c|}{$95 \%$ CI } \\
\cline { 3 - 8 } & & & & & & LL & 0.04 \\
LS-SP-SE & $0.47^{* * *}$ & $0.17^{* * *}$ & $0.75^{* * *}$ & $0.67^{* * *}$ & 0.07 & 0.12 \\
LS-SD-SE & $-0.56^{* * *}$ & $-0.32^{* * *}$ & $0.76^{* * *}$ & $0.58^{* * *}$ & 0.18 & 0.13 & 0.23 \\
\hline
\end{tabular}

Note: $* * * p<0.001$

Abbreviations: LS, life satisfaction; SE, self-esteem; SP, self-promotion; SD, self-deprecation. 
antecedents, considered as factors that make up life satisfaction, have a significant impact on people's subjective sense of personal value. In fact, life satisfaction includes social interactions, health and career, ${ }^{97}$ and overall evaluation of these different components correlates with self-esteem.

Secondly, the positive relationship between life satisfaction and self-promotion can be understood in the context of Regulatory Focus Theory, which implies that promotion-oriented individuals tend to progress in life and fulfill their expectations. ${ }^{98}$ Moreover, empirical findings have shown that promotion-focused individuals report experiencing higher levels of life satisfaction across different cultures. ${ }^{99}$ In turn, the negative correlation between self-deprecation and life satisfaction can be understood through studies of the sense of inferiority, incompetence or unworthiness. For example, it has been found that dissatisfaction with one's life is related to feelings of inadequacy, ${ }^{100}$ self-deprecation, ${ }^{101}$ and poor selfconcept. ${ }^{102}$

Finally, the mediatory role of self-promotion and self-deprecation suggests that the direct relationship between life satisfaction and self-esteem may be affected by these two self-presentation styles. In other words, it can be cautiously assumed that an overall sense of satisfaction with one's own life can lead to higher self-esteem when young people are aware of and show their strengths and talents. There is considerable data showing that global evaluation of life positively correlates with positive self-concept ${ }^{52}$ and selfpresentation involves improved self-esteem. ${ }^{103}$ Govindji and Harrington (p. 144) ${ }^{104}$ observe that "when we use our strengths, we feel good about ourselves, we are better able to achieve things, and we are working toward fulfilling our potential." Likewise, lower life satisfaction can elicit less positive self-esteem when people tend to undervalue their capabilities. This outcome is in line with some theoretical foundations and empirical evidence. For example, Powers and Zuroff ${ }^{106}$ have claimed that persistent and evident negative self-presentation decreases an already fragile sense of self-esteem. Therefore, the process of self-presentation by which people intentionally portray themselves ${ }^{105}$ might reinforce or weaken the link between overall satisfaction and self-esteem.

\section{Limitations}

Some limitations of this study need to be listed. First, the current research relied on self-report measures and could be limited by self-report biases. The use of other vectors for assessment (eg: parents, partners, friends) may reduce the impact of subjectivity and strengthen these outcomes. Second, the sample narrowed to young adults, and prevalently women does not permit the results to be generalized. Therefore, future studies should consider encompassing more distinct samples to provide more generalizable outcomes. Finally, the study was not longitudinal and thus it is implausible to infer causal relations among life satisfaction, self-esteem, and self-presentation.

\section{Conclusions and Implications}

The present study highlights the importance of considering the mediatory role of self-presentation on the relationship between life satisfaction and self-esteem. Our findings provide preliminary evidence that a subjective assessment of the quality of people's life can have a greater impact on their overall sense of worth and value when they improve their strengths and talents. Conversely, people's positive evaluations of their life may have a weaker effect on their opinion of themselves when they feel incompetent or insecure. Self-promotion and self-deprecation, as two important dimensions of self-presentation, act as psychological mechanisms that underlie the direct relationship between life satisfaction and self-esteem.

There are also several compelling implications that can be drawn from this study. The first one concerns the way of thinking about life satisfaction as an antecedent of selfesteem. The present result suggests that the relationship between both constructs is more complex (the majority of studies have shown that self-esteem predicted life satisfaction, rather than vice versa) and reciprocal (here, we have obtained life satisfaction as a predictor of self-esteem) and both life satisfaction and self-esteem may have a circular impact on one another. The second implication is related to the aspect of self-presentation as a mediator. Given that self-promotion and self-depreciation are expressions of the authentic (subjective) self and the people's actual beliefs about themselves, ${ }^{57}$ it seems important to consider their role in the assessment of the overall quality of life satisfaction and overall self-esteem. 


\section{Data Sharing Statement}

The datasets used during the current study are available from the corresponding author.

\section{Acknowledgment}

The authors thank the study participants.

\section{Author Contributions}

All authors made a significant contribution to the work reported, whether that is in the conception, study design, execution, acquisition of data, analysis and interpretation, or in all these areas; took part in drafting, revising or critically reviewing the article; gave final approval of the version to be published; have agreed on the journal to which the article has been submitted; and agree to be accountable for all aspects of the work.

\section{Disclosure}

The authors report no conflicts of interest in this work.

\section{References}

1. Patel AK, Tiwari SK, Singh L-S-S. Self-esteem and life satisfaction among university students of Eastern Uttar Pradesh of India: a demographical perspective. IJPP. 2018;9(3):328-386.

2. Civitci N, Civitci A. Self-esteem as mediator and moderator of the relationship between loneliness and life satisfaction in adolescents. Pers Individ Differ. 2009;47(8):954-958. doi:10.1016/j.paid.2009.07.022

3. Moksnes UK, Espnes GA. Self-esteem and life satisfaction in adolescents-gender and age as potential moderators. Qual Life Res. 2013;22(10):2921-2928. doi:10.1007/s11136-013-0427-4

4. Shi J, Wang L, Yao Y, Su N, Zhao X, Zhan C. Family function and self-esteem among Chinese university students with and without grandparenting experience: moderating effect of social support. Front Psychol. 2017;8:886. doi:10.3389/fpsyg.2017.00886

5. Hagen R, Havnen A, Hjemdal O, Kennair LEO, Ryum T, Solem S. Protective and vulnerability factors in self-esteem: the role of metacognitions, brooding, and resilience. Front Psychol. 2020;11:1447. doi:10.3389/fpsyg.2020.01447

6. Ouyang Y, Wang K, Zhang T, Peng L, Song G, Luo J. The influence of sports participation on body image, self-efficacy, and self-esteem in college students. Front Psychol. 2019;10:3039. doi:10.3389/fpsyg.2019.03039

7. Trzesniewski K, Donnellan MB, Robins R. Stability of self-esteem across the life span. J Pers Soc Psychol. 2003;84 (1):205-220. doi:10.1037//0022-3514.84.1.205

8. Roth M, Altmann TA. Comparison of the predictive validity of self-esteem level and directly measured self-esteem stability in the temporal prediction of psychological distress. Front Psychol. 2020;11:1770. doi:10.3389/fpsyg.2020.01770

9. Altmann T, Roth M. The Self-esteem Stability Scale (SESS) for cross-sectional direct assessment of self-esteem stability. Front. Psychol. 2018;9:91. doi:10.3389/fpsyg.2018.00091

10. Erol RY, Orth U. Self-esteem development from age 14 to 30 years: a longitudinal study. J Pers Soc Psychol. 2011;101 (3):607-619. doi:10.1037/a0024299
11. Lyu $\mathrm{H}, \mathrm{Du} \mathrm{G}$, Rios $\mathrm{K}$. The relationship between future time perspective and self-esteem: a cross-cultural study of Chinese and American college students. Front Psychol. 2019;10:1518. doi:10.3389/fpsyg.2019.01518

12. Crocker J, Lee SJ, Park LE. The pursuit od self-esteem: implications for good and evil. In: Miler AG, editor. The Social Psychology of Good and Evil. New York: Guilford Press; 2004:271-302.

13. Brown JD, Dutton KA, Cook KE. From the top down: self-esteem and self-evaluation. $\operatorname{Cog} n$ Emot. 2001;15(5):615-631. doi:10.1080/02699930143000004

14. Diener E, Diener M. Cross-cultural correlates of life satisfaction and self-esteem. J Pers Soc Psychol. 1995;68(4):653-663. doi:10.1037//0022-3514.68.4.653

15. Assor A, Roth G, Deci EL. The emotional costs of parents' conditional regard: a self-determination theory analysis. $J$ Pers. 2004;72(1):47-88. doi:10.1111/j.0022-3506.2004.00256.x

16. Pyszczynski T, Greenberg J, Solomon S, Show SJ, Schimel J. Converging toward an integrated theory of self-esteem: reply to Crocker and Nuer (2004), Ryan and Deci (2004), and Leary (2004). Psychol Bull. 2004;130(3):483-488. doi:10.1037/00332909.130.3.483

17. Knee CR, Canevello A, Amspoker AB, Cook A. Relationshipcontingent self-esteem and the ups and downs of romantic relationships. J Pers Soc Psychol. 2008;95(3):608-627. doi:10.1037/0022-3514.95.3.608

18. Cambron JM, Acitelli LK, Pettit JW. Explaining gender differences in depression: an interpersonal contingent self-esteem perspective. Sex Roles. 2009;61(11-12):751-761. doi:10.1007/ s11199-009-9616-6

19. Cambron MJ, Acitelli LK, Steinberg L. When friends make you blue: the role of friendship contingent self-esteem in predicting self-esteem and depressive symptoms. Pers Soc Psychol Bull. 2010;36(3):384-397. doi:10.1177/0146167209351593

20. Onoda K, Okamoto Y, Nakashima K, et al. Does low self-esteem enhance social pain? The relationship between trait self-esteem and anterior cingulate cortex activation induced by ostracism. Soc Cogn Affect Neurosci. 2010;5(4):385-391. doi:10.1093/scan/ nsq002

21. Brown DJ, Zeigler-Hill V. Self-Esteem. London: Routledge; 2017.

22. Crocker J. Social stigma and self-esteem: situational construction of self-worth. $\quad J \quad$ Exp Soc Psychol. 1999;35(1):89-107. doi:10.1006/jesp. 1998.1369

23. Crocker J, Luhtanen RK. Level of self-esteem and contingencies of self-worth: unique effects on academic, social, and financial problems in college students. Pers Soc Psychol Bull. 2003;29 (6):701-712. doi:10.1177/0146167203029006003

24. Martínez I, García JF. Impact of parenting styles on adolescents' self-esteem and internalization of values in Spain. Span J Psychol. 2007;10(2):338-348. doi:10.1017/s1138741600006600

25. Jordan CH, Zeigler-Hill V. Contingent self-esteem. Encycl Pers Individ Dif. 2018. doi:10.1007/978-3-319-28099-8_1125-1

26. Hart W, Kinrade CH, Breeden JCH. Revisiting narcissism and contingent self-esteem: a test of the psychodynamic mask model. Pers Individ Differ. 2020;162:110026. doi:10.1016/j. paid.2020.110026

27. Kashdan TB, Biswas-Diener R, King LA. Reconsidering happiness: the cost of distinguishing between hedonics and eudaimonia. J Posit Psychol. 2008;3(4):219-233. doi:10.1080/ 17439760802303044

28. Peterson C, Park N, Seligman MEP. Orientations to happiness and life satisfaction: the full life versus the empty life. $J$ Happiness Stud. 2005;6(1):25-41. doi:10.1007/s10902-004-1278-z

29. Schimmack U, Radhakrishnan P, Oishi S, Dzokoto V, Ahadi S. Culture, personality, and subjective well-being: integrating process models of life satisfaction. J Pers Soc Psychol. 2002;82 (4):582-593. doi:10.1037/0022-3514.82.4.582 
30. Czerw A. Diagnosing well-being in work context - eudemonic well-being in the workplace questionnaire. Curr Psychol. 2019;38 (4):331-346. doi:10.1007/s12144-017-9614-8

31. Lara R, Vázquez ML, Ogallar A, Godoy-Izquierdo D. Psychosocial resources for hedonic balance, life satisfaction and happiness in the elderly: a path analysis. Int J Environ Res Public Health. 2020;17(16):5684. doi:10.3390/ijerph17165684

32. Bauer JJ, McAdams DP, Pals JL. Narrative identity and eudaimonic well-being. J Happiness Stud. 2008;9(1):81-104. doi:10.1007/s10902-006-9021-6

33. Ryff CD, Keyes CLM. The structure of psychological well-being revisited. J Pers Soc Psychol. 1995;69(5):719-727. doi:10.1037/ 0022-3514.69.4.719

34. Disabato DJ, Goodman FR, Jarden A, Kashdan TB, Short JL. Different types of well-being? A cross-cultural examination of hedonic and eudaimonic well-being. Psychol Assess. 2016;28 (5):471-482. doi:10.1037/pas0000209

35. Diener E, Emmons RA, Larsen RJ, Griffin S. The satisfaction with life scale. J Pers Assess. 1985;49(1):71-75. doi:10.1207/ s15327752jpa4901_13

36. Pavot W, Diener E. The satisfaction with life scale and the emerging construct of life satisfaction. J Posit Psychologia. 2008;3(2):137-152. doi:10.1080/17439760701756946

37. Barker ET, Bornstein MH. Global self-esteem, appearance satisfaction, and self-reported dieting in early adolescence. J Early Adolesc. 2010;30(2):205-224. doi:10.1177/0272431609332936

38. Heady B, Veenhoven R, Wearing A. Top-down versus bottom-up theories of subjective well-being. Soc Indic Res. 1991;24 (1):81-100. doi:10.1007/1-4020-3742-2_15

39. Loewe N, Bagherzadeh M, Araya-Castillo L, Thieme C, BatistaFoguet JM. Life domain satisfactions as predictors of overall life satisfaction among workers: evidence from Chile. Soc Indic Res. 2014;118(1):71-86. doi:10.1007/s11205-013-0408-6

40. Lucas RE. Top-down and bottom-up models of life satisfaction judgments. Paper presented at the 6th International German Socio-Economic Panel Study User Conference; June 26; 2004. Available from: https://www.diw.de/documents/dokumente narchiv/17/diw_01.c.41891.de/paper2004_lucas.pdf. Accessed September 7, 2021.

41. Schyns P. Income and satisfaction in Russia. J Happiness Stud. 2001;2(2):173-204. doi:10.1023/A:101156463119

42. Kurnaz MF, Teke E, Günaydın HA. Relationship between self-esteem and life satisfaction: a meta-analysis study. REP. 2020;4(2):236-253.

43. Baumeister RF, Campbell JD, Krueger JI, Vohs KD. Does high self-esteem cause better performance, interpersonal success, happiness, or healthier lifestyles? Psychol Sci Public Interest. 2003;4 (1):1-44. doi:10.1111/1529-1006.01431

44. Goldsmith AH, Veum JR, Darity W. Unemployment, joblessness, psychological well-being and self-esteem: theory and evidence. J Soc Econ. 1997;26(2):133-158. doi:10.1016/S1053-5357(97) 90030-5

45. Schaffhuser K, Wagner J, Lüdtke O, Allemanda M. Dyadic longitudinal interplay between personality and relationship satisfaction: a focus on neuroticism and self-esteem. $J$ Res Pers. 2014;53:124-133. doi:10.1016/j.jrp.2014.08.007

46. Guasp Coll M, VNavarro-Mateu D, Giménez-Espert MC, PradoGascó VJ. Emotional intelligence, empathy, self-esteem, and life satisfaction in Spanish adolescents: regression vs. QCA models. Front Psychol. 2020;11:1629. doi:10.3389/fpsyg.2020.01629

47. Neff KD. Self-compassion, self-esteem, and well-being. Soc Personal Psychol Compass. 2011;5(1):1-12. doi:10.1111/j.17519004.2010.00330.x
48. Liang D, Xu D, Xia L, Ma X. Life satisfaction in Chinese ruralto-urban migrants: investigating the roles of self-esteem and affect balance. J Community Psychol. 2020;48(5):1651-1659. doi:10.1002/jcop. 22360

49. Farwa U, Hussain M, Afzal M, Gilani SA. The role of age, gender and socio-economic status in self-esteem and life satisfaction of nursing students. JHMN. 2019;62:178-186. doi:10.7176/JHMN

50. Sakellari E, Psychogiou M, Georgiou A, Papanidi M, Vlachou V, Sapountzi-Krepia D. Exploring religiosity, self-esteem, stress, and depression among students of a Cypriot university. J Relig Health. 2018;57(1):136-145. doi:10.1007/s10943-017-0410-4

51. Arslan C, Hamarta E, Uslu M. The relationship between conflict communication, self-esteem and life satisfaction in university students. Educ Res Rev. 2010;5(01):031-034.

52. Proctor CL, Linley PA, Maltby J. Youth life satisfaction: a review of the literature. $J$ Happiness Stud. 2009;10(5):583-630. doi:10.1007/s10902-008-9110-9

53. Gilman R, Huebner S. Characteristics of adolescents who report very high life satisfaction. J Youth Adolesc. 2006;35(3):311-319. doi:10.1007/s10964-006-9036-7

54. Boden JM, Fergusson DM, Horwood LJ. Does adolescent self-esteem predict later life outcomes? A test of the causal role of self-esteem. Dev Psychopathol. 2008;20(1):319-339. doi:10.1017/S0954579408000151

55. Mazur E, Kozarian L. Self-presentation and interaction in blogs of adolescents and young emerging adults. J Adolesc Res. 2010;25(1):124-144. doi:10.1177/0743558409350498

56. Rosenberg M. Conceiving the Self. New York, NY: Basic Books; 1979.

57. Wojciszke B. Autopromocja i autodeprecjacja: Kwestionariusz Stylów Autoprezentacji [Self-promotion and self-depreciation: SelfPresentation Questionnaire]. Psychol Jakości Życia. 2002;1 (1):145-171.

58. Leary MR. Self-Presentation Impression Management and Interpersonal Behavior. IA: Brown \& Benmark's; 1996.

59. Schlenker BR. Self-presentation. In: Leary MR, Tangney JP, editors. Handbook of Self and Identity. New York: The Guilford Press; 2012:542-570.

60. Valkenburg PM, Peter J. Online communication among adolescents: an integrated model of its attraction, opportunities, and risks. J Adolesc Health. 2011;48(2):121-127. doi:10.1016/j. jadohealth.2010.08.020

61. Vonk R. Impression formation and impression management: motives, traits, and likeability inferred from self-promoting and self-deprecating behavior. Soc Cogn. 1999;17(4):390-412. doi:10.1521/soco.1999.17.4.390

62. O'Mara EM, Kunz BR, Receveur A, Corbin S. Is self-promotion evaluated more positively if it is accurate? Reexamining the role of accuracy and modesty on the perception of self-promotion. Self Identity. 2019;18(4):405-424. doi:10.1080/15298868.2018.1465846

63. Turnley WH, Bolino MC. Achieving desired images while avoiding undesired images: exploring the role of self-monitoring in impression management. J Appl Psychol. 2001;86(2):351-360. doi:10.1037//0021-9010.86.2.351

64. Scopelliti I, Loewenstein G, Vosgerau J. You call it "selfexuberance"; i call it "bragging": miscalibrated predictions of emotional responses to self-promotion. Psychol Sci. 2015;26 (6):903-914. doi:10.1177/0956797615573516

65. Deschacht N, Maes B. Cross-cultural differences in self-promotion: a study of self-citations in management journals. J Occup Organ Psychol. 2017;90(1):77-94. doi:10.1111/joop.12162 
66. Rudman L. Self-promotion as a risk factor for women: the costs and benefits of counter stereotypical impression management. J Pers Soc Psychol. 1998;74(3):629-645. doi:10.1037//00223514.74.3.629

67. Radomska A, Tomczak J. Gelotophobia, self-presentation styles, and psychological gender. Psychol Test Assess Model. 2010;52 (2):191-201. doi:10.1037/t01870-000

68. Speer SA. Reconsidering self-deprecation as a communication practice. Social Psychol. 2019;58(4):806-828. doi:10.1111/ bjso. 12329

69. Owens TJ, Styker S, Goodman N, editors. Extending Self Esteem Theory and Research: Sociological and Psychological Currents. UK: Cambridge University Press; 2006.

70. Islam AKMN, Mäntymäki M, Benbasat I. Duality of self-promotion on social networking sites. Info Tech People. 2018;32(2). doi:10.1108/ITP-07-2017-0213

71. Żemojtel-piotrowska M, Bălţătescu S, Van Hiel A, Piotrowski J. Materialism, subjective well-being, and entitlement. J Soc Res Policy. 2013;4(2):79-91.

72. Ross CE, Van Willigen M. Education and the subjective quality of life. J Health Soc Behav. 1997;38(3):275-297. doi:10.2307/ 2955371

73. Błachnio A, Przepiorka A, Boruch W, Bałakier E. Selfpresentation styles, privacy, and loneliness as predictors of Facebook use in young people. Pers Individ Differ. 2016;94:26-31. doi:10.1016/j.paid.2015.12.051

74. Caprara GV, Alessandri G, Eisenberg N, et al. The positivity scale. Psychol Assess. 2012;24(3):701-712. doi:10.1037/ a0026681

75. Brown JD, Collins RL, Schmidt GW. Self-esteem and direct versus indirect forms of self-enhancement. J Pers Soc Psychol. 1988;55(3):445-453. doi:10.1037/0022-3514.55.3.445

76. Heller D, Watson D, Hies R. The role of person versus situation in life satisfaction: a critical examination. Psychol Bull. 2004;130 (4):574-600. doi:10.1037/0033-2909.130.4.574

77. Baumeister RF, Tice DM, Hutton DG. Self-presentational motivations and personality differences in self-esteem. J Pers. 1989;57(3):547-579. doi:10.1111/j.1467-6494.1989.tb02384.x

78. Horvath S, Morf CC. To be grandiose or not to be worthless: different routes to self-enhancement for narcissism and self-esteem. $J$ Res Pers. 2010;44(5):585-592. doi:10.1016/j. jrp.2010.07.002

79. McGregor I, Gailliot MT, Vasquez NA, Nash KA. Ideological and personal zeal reactions to threat among people with high self-esteem: motivated promotion focus. Pers Soc Psychol Bull. 2007;33(11):1587-1599. doi:10.1177/0146167207306280

80. Schütz A, Tice DM. Associative and competitive indirect self-enhancement in close relationships moderated by trait self-esteem. Eur J Soc Psychol. 1997;27(3):257-273. doi:10.1002/(SICI)1099-0992(199705)27:3<257:AIDEJSP820>3.0.CO;2-1

81. Heppner WL, Kernis MH. "Quiet ego" functioning: the complementary roles of mindfulness, authenticity, and secure high selfesteem. Psychol Inq. 2007;18(4):248-251. doi:10.1080/ 10478400701598330

82. Neenan M, Dryden W. Cognitive Behaviour Therapy an A-Z of Persuasive Arguments. New Jersey: Willey; 2006.

83. Peteet BJ, Brown CM, Lige QM, Lanaway DA. Impostorism is associated with greater psychological distress and lower self-esteem for African-American students. Curr Psychol. 2014;34(1):154-163. doi:10.1007/s12144-014-9248-Z

84. Jager J, Putnick DL, Bornstein MH. More than just convenient: the scientific merits of homogeneous convenience samples. Monogr Soc Res Child Dev. 2017;82(2):13-30. doi:10.1111/ mono. 12296
85. Mutter SA. Illusory correlation and group impression formation in young and older adults. J Gerontol B Psychol Sci Soc Sci. 2000;55(4):224-237. doi:10.1093/geronb/55.4.P224

86. Juczyński Z. Narzędzia Pomiaru w Promocji I Psychologii Zdrowia. Warszawa: PTP; 2001.

87. Rosenberg M. Society and Adolescent Self-Image. Middletown, CT: Wesleyan University Press; 1989.

88. Laguna M, Lachowicz-Tabaczek K, Dzwonkowska I. Skala samooceny SES Morrisa Rosenberga - polska adaptacja metody. Psychol Spol. 2007;2(4):164-176.

89. Hayes AF. Introduction to Mediation, Moderation, and Conditional Process Analysis: A Regression-Based Approach. New York, NY: The Guilford Press; 2017.

90. Leary MR. Making sense of self-esteem. Curr Dir Psychol Sci. 1999;8(1):32-35. doi:10.1111/1467-8721.00008

91. Kwan VSY, Kuang LL, Nhh H. Identifying the sources of self-esteem: the mixed medley of benevolence, merit and bias. Self Identity. 2009;8(2-3):176-195. doi:10.1080/15298860802504874

92. Buss DM. Human social motivation in evolutionary perspective: grounding terror management theory. Psychol Inq. 1997;8 (1):22-26. doi:10.1207/s15327965pli0801_3

93. Rey L, Extremera N, Pena M. Perceived emotional intelligence, self-esteem and life satisfaction in adolescents. Interv Psicosoc. 2011;20(2):227-234. doi:10.5093/in2011v20n2a10

94. MacDonald G, Saltzman JL, Leary MR. Social approval and trait self-esteem. J Res Pers. 2003;37(2):23-40. doi:10.1016/S00926566(02)00531-7

95. Schwalbe ML. Sources of self-esteem in work: what's important for whom? Work Occup. 1988;15(1):24-35. doi:10.1177/ 0730888488015001002

96. Pierce JL, Gardner DG. Self-esteem within the work and organizational context: a review of the organization-based self-esteem literature. $J$ Manag. 2004;30(5):591-622. doi:10.1016/j. jm.2003.10.001

97. Lounsburry JW, Park SH, Sundstrom E, Williamson JM, Pemberton AE. Personality, career satisfaction, and life satisfaction: test of directional model. J Career Assess. 2004;12 (4):395-406. doi:10.1177/1069072704266658

98. Zou X, Ingram P, Higgins ET. Social networks and life satisfaction: the interplay of network density and regulatory focus. Motiv Emot. 2015;39(5):693-713. doi:10.1007/s11031-015-9490-1

99. Lafrenière MA, Sedikides C, Lei X. Regulatory fit in self-enhancement and self-protection: implications for life satisfaction in the West and the East. J Happiness Stud. 2015;17 (3):1111-1123. doi:10.1007/s10902-015-9634-8

100. Upadyaya K, Vartainen M, Salmela-Aro K. From job demands and resources to work engagement, burnout, life satisfaction, depressive symptoms, and occupational health. Burn Res. 2016;3(4):101-108. doi:10.1016/j.burn.2016.10.001

101. Ben-Shlomo Y, Camfield L, Warner T; ESDE collaborative group. What are the determinants of quality of life in people with cervical dystonia? J Neurol Neurosurg Psychiatry. 2002;72 (5):608-614. doi:10.1136/jnnp.72.5.608

102. Judge TA, Erez A, Bono JE. The power of being positive: the relation between positive self-concept and job performance. Hum Perform. 1998;11(2/3):167-187. doi:10.1080/08959285.19 98.9668030

103. Gonzales AL, Hancock JT. Mirror, mirror on my Facebook wall: effects of exposure to Facebook on self-esteem. Cyberpsychol Behav Soc Netw. 2011;14(1-2):79-83. doi:10.1089/ cyber.2009.0411

104. Govindji R, Linley PA. Strengths use, self-concordance and well-being: implications for strengths coaching and coaching psychologists. ICPR. 2007;2(2):143-153. 
105. Powers TA, Zuroff DC. Interpersonal consequences of overt self-criticism: a comparison with neutral and self-enhancing presentations of self. J Pers Soc Psychol. 1988;54(5):1054-1062. doi:10.1037/0022-3514.54.6.1054
106. Strimbu N, O'Connell M. The relationship between self-concept and online self-presentation in adults. Cyberpsychol Behav Soc Netw. 2019;22(12):804-807. doi:10.1089/cyber.2019.0328

\section{Publish your work in this journal}

Psychology Research and Behavior Management is an international, peer-reviewed, open access journal focusing on the science of psychology and its application in behavior management to develop improved outcomes in the clinical, educational, sports and business arenas. Specific topics covered in the journal include: Neuroscience, memory and decision making; Behavior modification and management; Clinical applications; Business and sports performance management; Social and developmental studies; Animal studies. The manuscript management system is completely online and includes a very quick and fair peer-review system, which is all easy to use. Visit http://www. dovepress.com/testimonials.php to read real quotes from published authors. 